\title{
Influence of the hard segments content on the structure, viscoelastic and adhesion properties of thermoplastic polyurethane pressure sensitive adhesives
}

\author{
Mónica Fuensanta and José Miguel Martín-Martínez
}

\section{QUERY SHEET}

This page lists questions we have about your paper. The numbers displayed at left are hyperlinked to the location of the query in your paper.

The title and author names are listed on this sheet as they will be published, both on your paper and on the Table of Contents. Please review and ensure the information is correct and advise us if any changes need to be made. In addition, please review your paper as a whole for typographical and essential corrections.

Your PDF proof has been enabled so that you can comment on the proof directly using Adobe Acrobat. For further information on marking corrections using Acrobat, please visit http://journalauthors.tandf.co.uk/production/acrobat.asp; https://authorservices.taylorandfrancis.com/how-to-correct-proofs-with-adobe/

The CrossRef database (www.crossref.org/) has been used to validate the references.

\section{AUTHOR QUERIES}

Q1 Please check the values in the sentence “.... $\left(2,97,02,93,12,86,22,800 \mathrm{~cm}^{-1}\right)[\mathrm{AQ} 1]$, 50PPG50PTHF shows the main $\mathrm{C}-\mathrm{H}$ stretching bands of both 100PPG and 100PTHF polyurethanes $\left(2,96,82,93,22,85,72,800 \mathrm{~cm}^{-1}\right) \ldots$ ". and correct if necessary.

Q2 A disclosure statement reporting no conflict of interest has been inserted. Please correct if this is inaccurate.

Q3 The ORCID details of the authors have been validated against ORCID registry. please check the ORCID ID details of the authors. 


\title{
Influence of the hard segments content on the structure, viscoelastic and adhesion properties of thermoplastic polyurethane pressure sensitive adhesives
}

\author{
Q3 Mónica Fuensanta and José Miguel Martín-Martínez (D) \\ Adhesion and Adhesives Laboratory, Department of Inorganic Chemistry, University of Alicante, \\ Alicante, Spain
}

\begin{abstract}
New thermoplastic poly(ether-urethane)s (PUs) with different hard segments (HS) contents (13.9-24.4\% by weight) intended for pressure-sensitive adhesives (PSAs) have been synthesized by reacting different blends of polyether diols of different molecular weights - poly(propyleneglycol) (PPG) of molecular weight $2000 \mathrm{Da}$ and poly(tetrahydrofuran) (PTHF) of molecular weight $1000 \mathrm{Da}-4,4^{\prime}$ diphenylmethane diisocyanate, and 1,4-butanediol, the prepolymer method was used. The increase of the HS content increased the contribution of the associated by hydrogen bond urethane groups and decreased the degree of micro-phase separation in the PUs synthetized with PPG + PTHF blends, an increase of the thermal stability was also obtained. On the other hand, the PU made with $\mathrm{NCO} / \mathrm{OH}$ ratio of 1.10 showed unexpected properties because the contribution of the free urethane groups, the storage modulus and the temperature at the cross-over between the storage and loss moduli were higher than in the rest of the PUs synthesized with different $\mathrm{NCO} / \mathrm{OH}$ ratios. The PUs with HS contents of $14.0-16.7 \%$ by weight were typical general-purpose pressuresensitive adhesives (PSAs), whereas the PUs with HS content of $19-22 \%$ by weight were typical high shear PSAs. All PU PSAs followed the Dahlquist criterion and the one synthesized with $50 \mathrm{wt} \%$ PPG $+50 \mathrm{wt} \%$ PTHF and an $\mathrm{NCO} / \mathrm{OH}$ ratio of 1.10 showed an optimal balance between tack, shear resistance and $180^{\circ}$ peel strength values.
\end{abstract}

\section{ARTICLE HISTORY}

Received 29 April 2020

Revised 5 June 2020

Accepted 8 June 2020

\section{KEYWORDS}

Polyurethane; pressuresensitive adhesive; blends; polyether polyol; microphase separation; tack; shear; $180^{\circ}$ peel strength

\section{Introduction}

Pressure-sensitive adhesives (PSAs) are able to bond different substrates by applying light pressure for a short time, and they must be de-bonded without leaving residue on the substrate. PSAs are used in labels, tapes, protective films, and medical products (patches, bandages, electrodes, plasters, etc.) [1]. The viscoelastic properties determined the performance of the PSAs because the elastic-viscous components must be balanced for allowing adequate bonding and de-bonding upon contact with the substrate [2]. 
The main characteristic properties of the PSAs are tack, shear and peel adhesion. The tack is the initial immediate bond of a PSA with a substrate upon applying light pressure. The shear adhesion is the resistance of the PSA to flow under creep and is essential to ensure an adequate easy de-bonding from the substrate without leaving adhesive residues, i.e. it is related to the cohesion of the PSA. The force required to separate a PSA from a substrate surface is the peel adhesion.

Thermoplastic polyurethanes (PUs) have a great potential for designing PSAs due to their segmented structure constituted by hard (HS) and soft segments (SS). The hard segments are formed by reacting a diisocyanate and a short diol or diamine (chain extender), and they have low molecular weight and are polar; the soft segments are made of the polyol chains, they are less polar and significantly longer than the hard segments. Therefore, the hard and the soft segments are thermodynamically incompatible, and they exhibit micro-phase separation. The hard segments determine the mechanical properties of the PUs whereas the soft segments are related to their flexibility and the mobility of the polymeric chains [3-5]. Several studies [6-12] have revealed the importance of the PU morphology, i.e. the degree of micro-phase separation and the crystallinity of the hard and soft segments, on its properties (structure-properties relationships) such as the tensile strength, hardness, thermal stability and adhesion, among other. Martin et al. [6] have synthesized several PUs using 4,4'-diphenylmethane diisocyanate (MDI), 1,4-butane diol (BD) chain extender and poly(hexamethylene oxide) (PHMO) polyols of different molecular weights. They found that the increase of the soft segment length increased the degree of micro-phase separation, the average inter-domains spacing, the hard domain order, the hardness, the stiffness, and the opacity, the optimal mechanical properties were obtained in the PU made with PHMOs of molecular weights $650-850 \mathrm{~g} / \mathrm{mol}$. The influence of the molecular weight of the soft and hard segments, and the hard segments content on the structure-property relationship have been analyzed in thermoplastic polyurethanes synthesized with poly (tetramethylene oxide) (PTMO) soft segment, linear symmetric $p$-phenylene diisocyanate (pPDI), and BD chain extender [7]. These PUs exhibited micro-phase separation and the increase of the HS content increased the moduli and the tensile strength, enhanced the degree of micro-phase separation and the storage modulus in the rubbery plateau region. Rogulska et al. [8] have synthesized three series of TPUs with different chain extenders, MDI and 40-60 mol\% PTMO with a molecular weight of $1000 \mathrm{~g} / \mathrm{mol}$, the one-shot method was used. The TPUs were amorphous and the hardness and elongation-at-break increased but the elastic modulus and the tensile strength decreased by increasing the SS content. On the other hand, the adhesion properties of the PUs synthesized with MDI, BD chain extender and polyadipate of 1,4-butanediol $(\mathrm{MW}=2440 \mathrm{~g} / \mathrm{mol})$ containing different hard $/$ soft segment ratios were evaluated by $\mathrm{T}$ peel tests of solvent-wiped polyvinyl chloride (PVC)/polyurethane adhesive joints, the T-peel strength increased by increasing the HS content [9-11]. Thermoplastic polyurethanes synthesized with polytetrahydrofuran/polycaprolactone (PTHF/PCL) blends have been prepared, the ones made with PCL + PTHF blends enhanced the microphase separation and higher elongation-at-break and toughness, as compared to the TPUs made with one type of polyol only, have been obtained [12]. Therefore, the use of polyols blends of different nature for synthesizing PUs seems an interesting strategy 
for changing the interactions between the hard and the soft segments obtained by using one polyol only, this allows the balance of the adhesion and cohesion properties, an aspect of critical relevance in PSAs.

Different strategies have been proposed to improve the performance of PU PSAs. In general, the PU PSAs with excellent tack show poor cohesion and the PU PSAs with good cohesion have low tack. Tackifiers can be added to increase the tack of the PU PSAs [13] and the addition of cross-linkers to increase their cohesion has been proposed [14-16]. On the other hand, silane terminated polyurethane have been synthesized for imparting tack to moisture-curable PU PSAs [17, 18], and the use of hydroxyl-terminated polybutadiene (HTPB) polyol produced a higher degree of microphase separation between the hard and soft segments and a good balance between tack and cohesion was reached [19-23]. In fact, the increase of the HTPB content increased the tack of the PUs, whereas the increase of its molecular weight decreased the adhesion properties. Recently, different PU PSAs synthesized with blends of polypropylene glycols (PPGs) of different molecular weights and MDI showed good tack at $10-37^{\circ} \mathrm{C}$ but low peel strength and cohesion [24]; furthermore, the PU PSAs synthesized with lower HS content showed poor shear strength but high tack and peel strength, whereas the increase of the HS content increased the shear strength and the peel strength values, but the tack was low [25]. Therefore, an optimal HS content should be obtained for balancing the adhesion and cohesion properties of the PU PSAs.

In this study, the influence of the HS content has been considered for obtaining PU PSAs with good tack, peel adhesion and cohesion. The segmented structure and the degree of micro-phase separation of the PUs have been modified by changing their HS content in two ways: (i) use of blends of polyether polyols with (poly(propyleneglycol) - PPG) and without (poly(tetrahydrofuran) - PTHF) pendant methyl group and different molecular weights (the interactions between the SS is changed mainly); (ii) change of the $\mathrm{NCO} / \mathrm{OH}$ ratio (1.05-1.35) (the interactions between the HS is changed mainly) (Figure 1). The absence of the pendant methyl group will allow more net van der Waals interactions between the SS in the PU reducing the mobility of the polymer chains but increasing its cohesion and mechanical properties. Thus, the mixing of PTHF with PPG polyols in the synthesis of the PUs will modify the extent of interactions between the soft segments, in a different manner by changing the NCO/OH ratio.

\section{Experimental}

\subsection{Materials}

The PUs were synthesized by reacting 4,4'-diphenylmethane diisocyanate (MDI) Desmodur ${ }^{\circledR} 44 \mathrm{MC}$ flakes supplied by Covestro (Leverkusen, Germany) -, different blends of poly(propyleneglycol) (PPG) of molecular weight $2000 \mathrm{~g} / \mathrm{mol}$ - Alcupol $^{\circledR}$ D2021 supplied by Repsol (Madrid, Spain) - and poly(tetrahydrofuran) of molecular weight $1000 \mathrm{~g} / \mathrm{mol}$ (PTHF) supplied by Sigma Aldrich (St. Louis, MO). The polyols were melted and dried at $80^{\circ} \mathrm{C}$ under reduced pressure $(300 \mathrm{mbar})$ for $2 \mathrm{~h}$ before used. Dibutyl tin dilaurate (DBTDL) was used as catalyst and 1,4-butanediol (BD) was used as chain extender, both were supplied by Sigma Aldrich (St. Louis, MO). Methyl ethyl ketone (MEK) supplied by Jaber S.A. (Almansa, Spain) was used to dissolve the PUs 


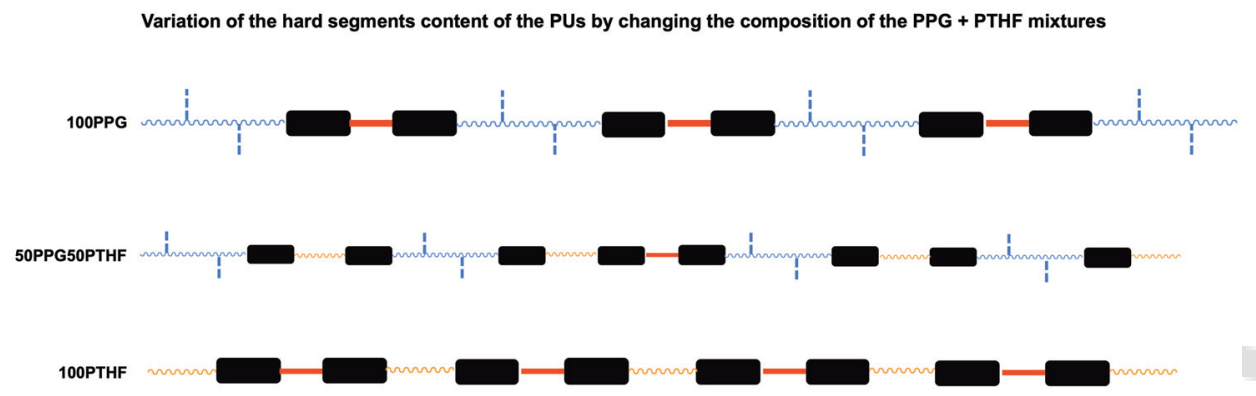

Variation of the hard segments content of the PUs by changing the $\mathrm{NCO} / \mathrm{OH}$ ratio


for adequate coating on polyethylene terephthalate (PET) films for obtaining the PU PSAs.

Figure 1. Scheme of the PU structures obtained by changing the hard segments content by using different PPG + PTHF blends and $\mathrm{NCO} / \mathrm{OH}$ ratio.

\subsection{Synthesis of the polyurethanes made with PPG + PTHF blends}

The PUs were synthesized by using the prepolymer method in $500 \mathrm{~mL}$ glass reactor under inert atmosphere (dried nitrogen) and an anchor-shaped stirrer coupled to Heidolph overhead stirrer RZR-2000 (Kelheim, Germany) was used [24]. NCO/OH molar ratios between 1.05 and 1.35 were used, the $-\mathrm{OH}$ groups of the 1,4 butanediol chain extender were considered in the calculations. MDI was melted at $80^{\circ} \mathrm{C}$ in the reactor, and PPG, PTHF or PPG + PTHF blends were added under stirring at $250 \mathrm{rpm}$ for $30 \mathrm{~min}$. Afterwards, $0.04 \mathrm{mmol}$ of catalyst (DBTDL) was added and the stirring was decreased to $80 \mathrm{rpm}$. The reaction lasted for $2 \mathrm{~h}$ and the amount of free NCO content was determined by dibutylamine titration. Then, the chain extender (BD) was added under stirring at $80^{\circ} \mathrm{C}$ and $80 \mathrm{rpm}$ for $5 \mathrm{~min}$. The scheme of the synthesis of the PUs is shown in Figure 2.

The PU PSAs were prepared according to the procedure described in Ref. [24]. $10 \mathrm{~mL}$ MEK solution containing $4 \mathrm{~g}$ solid PU was spread on PET film $(50 \mu \mathrm{m}$ thick) and the thickness of the PU coating was adjusted with a metering rod of $400 \mu \mathrm{m}$. The solvent was removed at room temperature for $72 \mathrm{~h}$ for obtaining the PU PSAs. The thicknesses of the PUs on the PET films were $40-50 \mu \mathrm{m}$. 
181

182

183

184

185

186

187

188

189

190

191

192

193

194

195

196

197

198

199

200

201

202

203

204

205

206

207

208

209

210

211

212

213

214

215

216

217

218

219

220

221

222

223

224

225

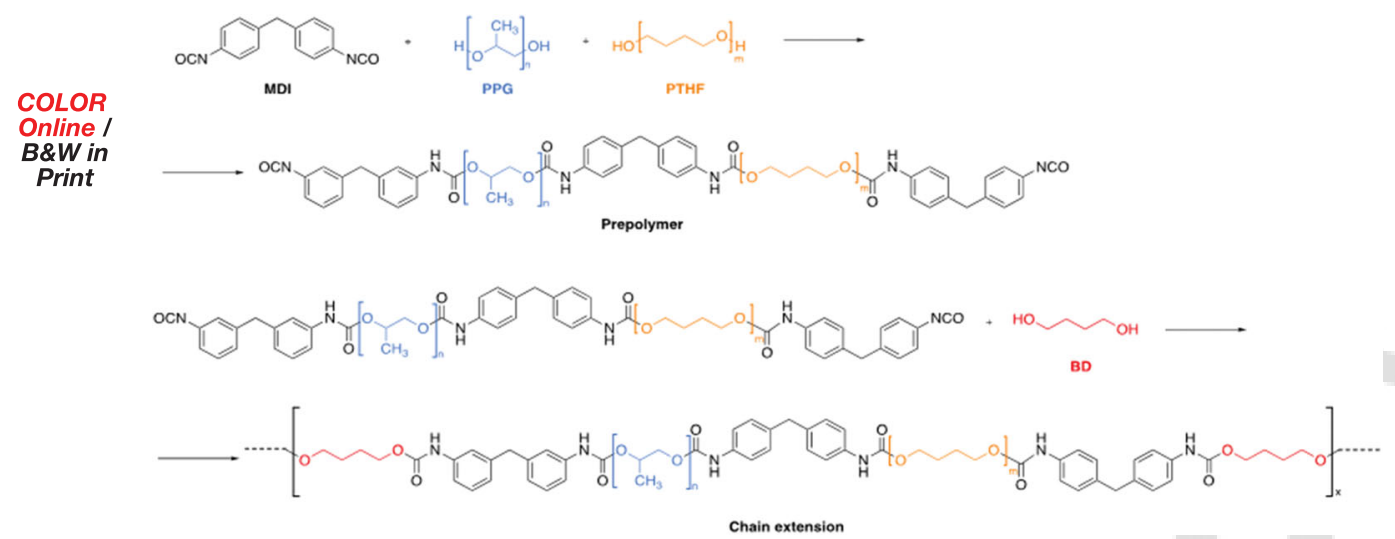

Figure 2. Scheme of the synthesis of the polyurethanes made with PPG + PTHF blends.

\subsection{Experimental techniques}

\subsubsection{Attenuated total reflectance Fourier transform infrared (ATR-IR) spectroscopy}

Attenuated total reflection infrared spectra of the PUs were obtained in absorbance mode in a Tensor 27 FT-IR spectrometer (Bruker Optik GmbH, Erlinger, Germany) by using Golden Gate single reflection diamond, recording 64 scans with a resolution of $4 \mathrm{~cm}^{-1}$ in the range of wavenumbers from 4000 to $400 \mathrm{~cm}^{-1}$ [24].

\subsubsection{Differential scanning calorimetry (DSC)}

Differential scanning calorimetry was used to obtain the structural properties of the PUs, a DSC Q100 calorimeter (TA Instrument, New Castle, DE) under the nitrogen atmosphere (flow rate $=50 \mathrm{~mL} / \mathrm{min}$ ) was used. $7-8 \mathrm{mg}$ sample was heated in hermeticsealed aluminum pan from -80 to $150^{\circ} \mathrm{C}$, cooled at $-80^{\circ} \mathrm{C}$ and heated again from -80 to $200^{\circ} \mathrm{C}$, the heating and cooling rates were $10^{\circ} \mathrm{C} / \mathrm{min}$ [24]. The glass transition temperatures of the PUs were obtained from the second DSC heating runs.

\subsubsection{Thermal gravimetric analysis (TGA)}

Thermal gravimetric analysis was also used to obtain the structural properties of the PUs, a TGA Q500 equipment (TA Instruments, New Castle, DE) under the nitrogen atmosphere (flow rate $=50 \mathrm{~mL} / \mathrm{min}$ ) was used. $10 \mathrm{mg}$ sample was placed in a platinum crucible and it was heated from 35 to $800^{\circ} \mathrm{C}$ by using a heating rate of $10^{\circ} \mathrm{C} / \mathrm{min}$ [24].

\subsubsection{Plate-plate rheology}

The viscoelastic properties of the PUs were assessed in a DHR-2 rheometer (TA Instruments, New Castle, DE, USA) using parallel plate-plate geometry, a stainless steel plate of $20 \mathrm{~mm}$ diameter and a gap of $0.40 \mathrm{~mm}$ were used. Temperature sweep experiments were carried out from -15 to $120^{\circ} \mathrm{C}$, by using a heating rate of $5{ }^{\circ} \mathrm{C} / \mathrm{min}$ and a frequency of $1 \mathrm{~Hz}$. Furthermore, frequency sweep experiments were carried out at $25^{\circ} \mathrm{C}$ by using $2.5 \%$ strain amplitude in the angular frequency range from 0.01 to $100 \mathrm{rad} / \mathrm{s}[24]$. 


\subsubsection{Adhesion properties}

The adhesion properties of the PU PSAs were assessed at $25^{\circ} \mathrm{C}$ by probe tack, $180^{\circ}$ peel strength and creep test under shear.

The probe tack of the PU PSAs was measured at $25^{\circ} \mathrm{C}$ by using a flat end cylindrical stainless-steel probe of $3 \mathrm{~mm}$ diameter in a TA.XT2i Texture Analyzer (Stable Micro Systems, Surrey, UK) [24]. The probe was approached slowly to the PU PSA surface applying a load of $5 \mathrm{~N}$ for $1 \mathrm{~s}$ and it was pulled out at $10 \mathrm{~mm} / \mathrm{s}$. The maximum of the stress-strain curve was taken as the tack of the PU PSA. At least five replicates were carried out and averaged.

The $180^{\circ}$ peel strength of aluminum 5754/PU PSA joints was carried out in an Inston 4411 universal testing machine (Instron Ltd. Buckinghamshire, UK), the pulling rate was $152 \mathrm{~mm} / \mathrm{min}$ [24]. The PU PSA strips have dimensions of $30 \mathrm{~m} \times 300 \mathrm{~mm} \times$ $0.5 \mathrm{~mm}$ and they were joined to clean aluminum 5754 pieces of dimensions $30 \mathrm{~mm} \times$ $150 \mathrm{~mm} \times 1.5 \mathrm{~mm}$, the joints were made by passing 30 times a $2 \mathrm{~kg}$ rubber coated roller. Five replicates were tested and averaged for each joint.

The creep tests under shear of the PU PSAs were carried out in a Shear-10 equipment (ChemInstruments, Fairfell, OH). PU PSA strips of $2.4 \mathrm{~cm} \times 20 \mathrm{~cm}$ were attached to the center of a clean polished stainless steel 304 piece. PU PSA area of $2.5 \mathrm{~mm} \times$ $2.5 \mathrm{~mm}$ was joined to the stainless steel and a $2 \mathrm{~kg}$ rubber-coated roller was passed over the joint. The PU PSA-stainless steel joint was placed on the holder hanging a weight of $1 \mathrm{~kg}$ at the bottom [25]. The creep resistance at $25^{\circ} \mathrm{C}$ of the PU PSAs is related to their cohesion properties and was obtained as the "holding time", i.e. the time needed for the PU PSA strip to fall down. Three replicates were tested for each PU PSA and the results obtained were averaged.

\section{Results and discussion}

\subsection{Variation of the hard segments content of the PUs by changing the composition of the PPG + PTHF blends}

Five PUs with hard segments contents (HS \%) between 13.9 and $24.4 \%$ by weight were synthesized by changing the composition of the PPG + PTHF mixtures in the soft segments (Table 1). The molecular structure of the PUs synthesized with higher PPG content will have lower HS content and longer polymeric chains ( $M W=2000 \mathrm{~g} / \mathrm{mol}$ ) with more pendant alkyl groups, these groups will disturb the interactions between the soft segments (Figure 1). However, the PUs synthesized with a higher content of PTHF will show higher HS content and shorter polymeric chains (MW $=1000 \mathrm{~g} / \mathrm{mol}$ ), higher amount of shorter soft segments and more net interactions between them. Therefore, the PUs made with different PPG + PTHF blends will have different degrees of microphase separation and mobility of the soft segments, these will determine the performance of the PU PSAs.

The structure of the PUs was analyzed by ATR-IR spectroscopy, DSC and TGA. To analyze the structure of the PUs synthesized with PPG + PTHF mixtures, three different regions of the ATR-IR spectra are considered (Figure 3). The $\mathrm{C}-\mathrm{H}$ stretching at $3100-2700 \mathrm{~cm}^{-1}$ and the $\mathrm{C}-\mathrm{O}-\mathrm{C}$ stretching at $1180-900 \mathrm{~cm}^{-1}$ regions are influenced by the absorption bands of the PPG and PTHF polyols. The C-H stretching of 100PPG 
Table 1. Nomenclature, composition and relative contributions of the free and hydrogen bonded urethane groups of the PUs synthesized with PPG + PTHF mixtures.

\begin{tabular}{lcccccc}
\hline & & & & \multicolumn{2}{c}{ Relative contribution of species (\%) } \\
\cline { 4 - 6 } PU & & & & $\begin{array}{c}\text { Free urethane } \\
\left(1730-1729 \mathrm{~cm}^{-1}\right)\end{array}$ & $\begin{array}{c}\text { H-bonded urethane } \\
\left(1711-1709 \mathrm{~cm}^{-1}\right)\end{array}$ \\
\hline 100PPG & PPG (wt\%) & PTHF (wt\%) & NCO/OH & HS (\%) & 55 & 45 \\
75PPG25PTHF & 700 & 0 & 1.20 & 13.9 & 48 & 52 \\
50PPG5PTHF & 50 & 25 & 1.20 & 16.7 & 38 & 62 \\
25PPG75PTHF & 25 & 50 & 1.20 & 19.4 & 38 & 74 \\
100PTHF & 0 & 75 & 1.20 & 21.8 & 26 & 62 \\
\hline
\end{tabular}

polyurethane appears at 2970,2930 , and $2868 \mathrm{~cm}^{-1}$, whereas the one of 100PTHF polyurethane can be distinguished at 2939, 2853, and $2796 \mathrm{~cm}^{-1}$. 75PPG25PTHF polyurethane displays the same $\mathrm{C}-\mathrm{H}$ stretching bands than 100PPG polyurethane Q1 $\left(2,97,02,93,12,86,22,800 \mathrm{~cm}^{-1}\right), 50$ PPG50PTHF shows the main $\mathrm{C}-\mathrm{H}$ stretching bands of both 100PPG and 100PTHF polyurethanes $\left(2,96,82,93,22,85,72,800 \mathrm{~cm}^{-1}\right)$, and 25PPG75PTHF polyurethane presents the same $\mathrm{C}-\mathrm{H}$ stretching bands than 100PTHF polyurethane $\left(2939,2853\right.$, and $2796 \mathrm{~cm}^{-1}$ ) (Figure 3(a)). Similarly, the C-O-C stretching bands of the 100PPG and 100PTHF polyurethanes appear at 1089 and $1103 \mathrm{~cm}^{-1}$ respectively, and the PUs synthesized with 25-50 wt\% PPG + 75-50 wt\% PTHF show the $\mathrm{C}-\mathrm{O}-\mathrm{C}$ stretching at $1095 \mathrm{~cm}^{-1}$, indicating different interactions between the soft segments than the ones in the PUs made with one polyol only (Figure 3(b)).

The structural differences in the hard segments between the PUs synthesized with $\mathrm{PPG}+\mathrm{PTHF}$ mixtures are observed in the $\mathrm{C}=\mathrm{O}$ stretching band of the ATR-IR spectra (Figure $3(\mathrm{c})$ ). The curve fitting of the $\mathrm{C}=\mathrm{O}$ stretching band shows two contributions due to free urethane (i.e. not in hard domains) at $1730-1729 \mathrm{~cm}^{-1}$ and associated by hydrogen bond (H-bonded) urethane groups at $1711-1709 \mathrm{~cm}^{-1}$. According to Table 1, 100PPG polyurethane shows almost similar contributions of free and $\mathrm{H}$ bonded urethane groups whereas the H-bonded urethane groups are dominant in 100PTHF polyurethane. The increase of the HS content and the PTHF content in the polyols blends increase the contribution of the H-bonded urethane groups (52-62\%), indicating a decrease of the degree of micro-phase separation. Furthermore, the PUs synthesized with $50-75 \mathrm{wt} \%$ PTHF which have less percentage of pendant groups and a slight difference in HS content (19.4-21.8\%), show similar contributions of free (38\%) and H-bonded (62\%) urethane groups.

The structure of the PUs synthetized with PPG + PTHF mixtures was also assessed by TGA. Above $350^{\circ} \mathrm{C}$, the thermal stability of the PUs increased when they contain PTHF due to the more net interactions between the soft segments and higher HS content (Figure $4(\mathrm{a})$ ) and, therefore, the temperature at which $50 \mathrm{wt} \%$ is lost increases as the PTFH content increases (Table 3); this indicates lower degree of micro-phase separation in the PUs containing PTHF and restricted mobility of the HS due to the increase of the H-bonded urethane groups content [26], in agreement with the ATR-IR spectra. Similarly, the temperature at which $5 \mathrm{wt} \%$ is lost in the PUs increases as the PTFH increases, except in 75PPG25PTHF in which the value is lower due to similar content of free and $\mathrm{H}$-bonded urethane groups. On the other hand, the DTGA plots (Figure 4(b)) show two main decompositions at $315-341^{\circ} \mathrm{C}$ (degradation of the 
316

317

318

319

320

321

322

323

324

325

326

327

328

329

330

331

332

333

334

335

336

337

338

339

340

341

342

343

344

345

346

347

348

349

350

351

352

353

354

355

356

357

358

359

360



(b) $100 \mathrm{PPG}$


Figure 3. ATR-IR spectra of the PUs synthetized with PPG + PTHF mixtures: (a) $\mathrm{C}-\mathrm{H}$ stretching region at $3100-2700 \mathrm{~cm}^{-1}$, (b) $\mathrm{C}-\mathrm{O}-\mathrm{C}$ stretching region at $1180-900 \mathrm{~cm}^{-1}$, and (c) $\mathrm{C}=0$ stretching region at $1800-1650 \mathrm{~cm}^{-1}$.

urethane hard domains) and $371-401{ }^{\circ} \mathrm{C}$ (degradation of the soft domains). As expected, the temperature of decomposition and the weight loss of the soft segments in the PUs increase by increasing their PTHF content (Table 2) and, in general, the temperatures of decomposition and the weight losses of the urethane hard domains too, 75PPG25PTHF is an exception because a higher temperature of decomposition than expected is obtained. Thus, the interactions between the hard urethane domains in 75PPG25PTHF polyurethane are stronger than in the rest of the PUs likely due to the higher content of the high molecular weight PPG which may favour the creation of a segmented structure. 
361

362

363

364

365

366

367

368

369

370

371

372

373

374

375

376

377

378

379

380

381

382

383

384

385

386

387

388

389

390

391

392

393

394

395

396

397

398

399

400

401

402

403

404

405
COLOR

Online I

$B \& W$ in

Print

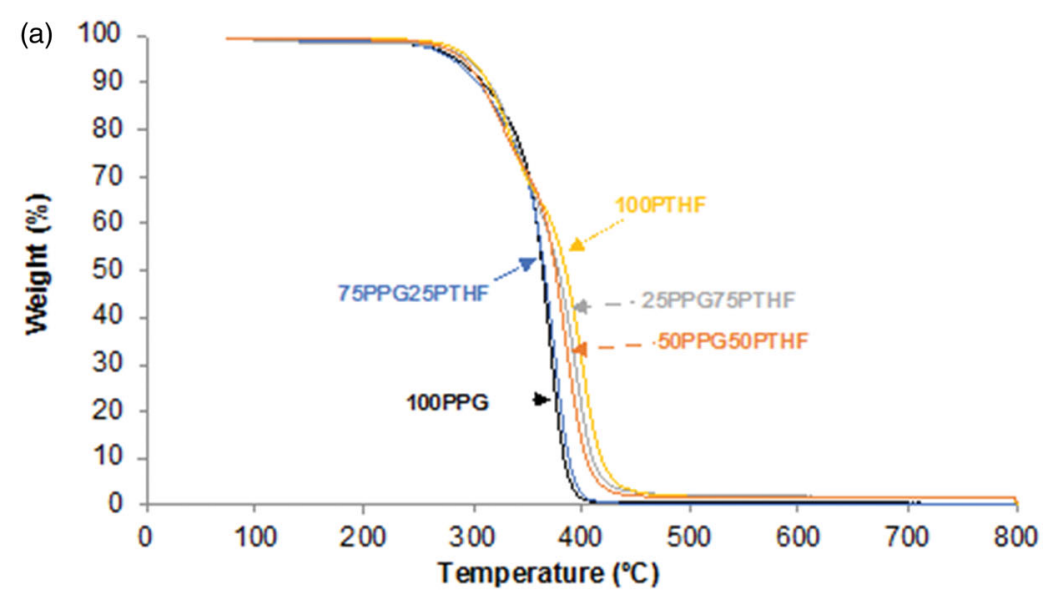

(b)



Figure 4. Variation of (a) the weight and (b) the derivative of the weight as a function of the temperature for PUs synthetized with PPG + PTHF mixtures.

Table 2. Temperatures and weight losses of the thermal decompositions obtained from DTGA experiments in the PUs synthetized with PPG + PTHF mixtures.

\begin{tabular}{lccccccc}
\hline & & & \multicolumn{2}{c}{ 1st degradation } & & \multicolumn{2}{c}{ 2nd degradation } \\
PU & $T_{5 \%}\left({ }^{\circ} \mathrm{C}\right)$ & $T_{50 \%}\left({ }^{\circ} \mathrm{C}\right)$ & $T_{1}\left({ }^{\circ} \mathrm{C}\right)$ & Weight loss $1(\%)$ & & $T_{2}\left({ }^{\circ} \mathrm{C}\right)$ & Weight loss $(\%)$ \\
\hline 100PPG & 287 & 365 & 315 & 17 & & 371 & 82 \\
75PPG25PTHF & 284 & 366 & 333 & 21 & & 375 & 78 \\
50PPG50PTHF & 292 & 376 & 324 & 27 & & 386 & 71 \\
25PPG75PTHF & 295 & 379 & 341 & 36 & & 395 & 61 \\
100PTHF & 299 & 385 & 335 & 33 & & 401 & 65 \\
\hline
\end{tabular}

The structure of the PUs synthetized with PPG + PTHF mixtures was also investigated by DSC. The DSC traces of the PUs show one glass transition temperature of the soft segments $\left(T_{\mathrm{g}}\right)$ between -50 and $-47^{\circ} \mathrm{C}$ (Figure 5). The $T_{\mathrm{g}}$ values of the polyols are $-69^{\circ} \mathrm{C}$ for PPG and lower than $-80^{\circ} \mathrm{C}$ for PTHF. The $T_{\mathrm{g}}$ values of the PUs are not very different even they have significant differences in HS content, this can be 
COLOR

Table 3. Values of the temperature $\left(T_{\text {cross-over }}\right)$ and modulus $\left(G_{\text {cross-over }}\right)$ at the crossing of the storage and the loss moduli, storage modulus at $25^{\circ} \mathrm{C}\left(\mathrm{G}^{\prime}{ }_{1 \mathrm{~Hz}}\right)$, and storage moduli at $0.1 \mathrm{rad} / \mathrm{s}$ and $100 \mathrm{rad} / \mathrm{s}$ in the PUs synthetized with PPG + PTHF mixtures.

\begin{tabular}{|c|c|c|c|c|c|c|}
\hline \multirow[b]{2}{*}{ PU } & \multicolumn{3}{|c|}{ Temperature sweep } & \multicolumn{3}{|c|}{ Frequency sweep at $25^{\circ} \mathrm{C}$} \\
\hline & $T_{\text {cross-over }}\left({ }^{\circ} \mathrm{C}\right)$ & $G_{\text {cross-over }}(\mathrm{Pa})$ & $\mathrm{G}^{\prime}{ }_{1 \mathrm{~Hz}}$ at $25^{\circ} \mathrm{C}(\mathrm{Pa})$ & $\mathrm{G}_{0.1 \mathrm{rad} / \mathrm{s}}^{\prime}(\mathrm{kPa})$ & $\mathrm{G}^{\prime}{ }_{100 \mathrm{rad} / \mathrm{s}}(\mathrm{kPa})$ & $\begin{array}{c}\mathrm{G}_{1}^{\prime}{ }_{100 \mathrm{rad} / \mathrm{s}} / \\
\mathrm{G}^{\prime}{ }_{0.1 \mathrm{rad} / \mathrm{s}}\end{array}$ \\
\hline 100PPG & 1 & $1.2 \cdot 10^{5}$ & $1.1 \cdot 10^{6}$ & 0.02 & 127.0 & 6350 \\
\hline 75PPG25PTHF & 27 & $1.2 \cdot 10^{5}$ & $1.5 \cdot 10^{5}$ & 3.4 & 477.4 & 140 \\
\hline 50PPG50PTHF & 38 & $1.4 \cdot 10^{5}$ & $2.8 \cdot 10^{5}$ & 14.8 & 730.5 & 49 \\
\hline 25PPG75PTHF & 35 & $1.9 \cdot 10^{5}$ & $3.6 \cdot 10^{5}$ & 22.8 & 946.7 & 42 \\
\hline
\end{tabular}

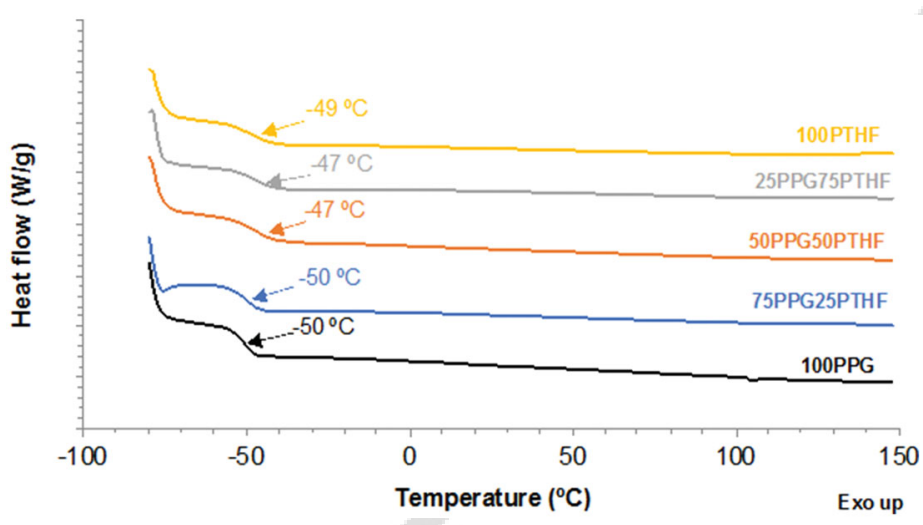

Figure 5. DSC thermograms of the PUs synthetized with PPG + PTHF mixtures. Second heating run.

ascribed to the less ability of the low molecular weight PTHF to produce segmented structure. On the other hand, no melting or crystallization peaks appear in the DSC traces of the PUs indicating the absence of crystalline domains (amorphous structure). In fact, the increase of the PTHF content (MW $=1000 \mathrm{~g} / \mathrm{mol}$ ) which does not have pendant groups and has short length, produces higher amount of short HS in the PU, this inhibits the formation of a segmented structure and enhances the soft-hard segments mixing and crystallization cannot be expected $[26,27]$. On the other hand, the PUs have significant contents of hard segments $(13.9-24.4 \%)$ and the existence of $\mathrm{H}$ bonding between urethane groups is shown in the ATR-IR spectra. Thus, a melting transition at high temperature due to the hard domains can be reasonably expected in the DSC traces of the PUs. Mattia and Painter [28] have shown that the formation of the ordered structures due to hydrogen bond interactions in segmented polyurethanes occurred at temperatures well below the glass transition and the melting endotherms could not be detected because these ordered structures were largely two-dimensional. On the other hand, the short-range hard segments dissolved in the soft segments are amorphous and the long-range hard segments mixed with and separated from the soft blocks form crystallites [29]. Therefore, the PUs should have small crystallites even the DSC traces do not show any melting peak.

The viscoelastic properties are critical in the performance of the pressure-sensitive adhesives (PSAs). The variation of the storage modulus $\left(\mathrm{G}^{\prime}\right)$ of the PUs synthetized with PPG + PTHF mixtures as a function of the temperature (Figure 6(a)) shows an 
451

452

453

454

455

456

457

458

459

460

461

462

463

464

465

466

467

468

469

470

471

472

473

474

475

476

477

478

479

480

481

482

483

484

485

486

487

488

489

490

491

492

493

494

495
COLOR

Online I

$B \& W$ in
Print

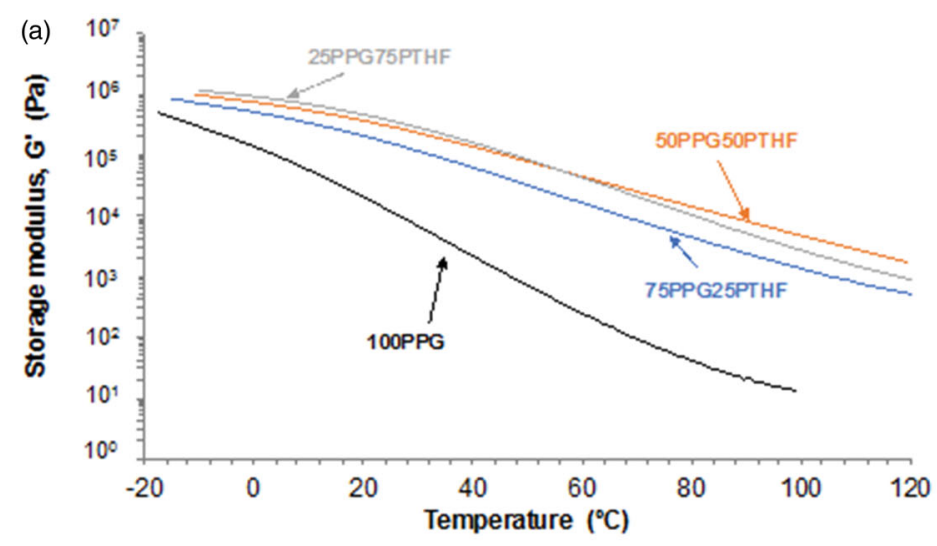

(b)



Figure 6. (a) Variation of the storage modulus (G) as a function of the temperature for PUs synthetized with PPG + PTHF mixtures, and (b) variation of the storage $(G)$ and loss (G) moduli as a function of the temperature for 50PPG50PTHF.

increase of $\mathrm{G}^{\prime}$ by increasing the amount of PTHF and the variation of $\mathrm{G}^{\prime}$ with the temperature becomes less important due to the increase of the HS content; the rheological curve of the 100PTHF polyurethane is not plotted because it does not show PSA property. Figure 6(b) shows the existence of a cross-over between the storage $\left(G^{\prime}\right)$ and the loss $\left(G^{\prime \prime}\right)$ moduli. The increase of the HS content and the PTHF content increase the temperatures and the moduli at the cross-over of $\mathrm{G}^{\prime}$ and $\mathrm{G}^{\prime \prime}$ in the PUs, due to the increase of the H-bonded urethane groups and lower micro-phase separation (Table 3). The temperatures at the cross-over of the PUs synthetized with PPG + PTHF mixtures are higher than $25^{\circ} \mathrm{C}$. On the other hand, according to the Dahlquist criterion, an adequate tack in PSAs should be obtained when the $\mathrm{G}^{\prime}$ value measured at $25^{\circ} \mathrm{C}$ and $1 \mathrm{~Hz}$ frequency is lower than $3 \times 105 \mathrm{~Pa}$ [30]. All PUs synthetized with PPG + PTHF mixtures have $\mathrm{G}^{\prime}$ values at $25^{\circ} \mathrm{C}$ of $(1.5-3.6) \times 10^{5} \mathrm{~Pa}$ which anticipates good tack (Table 3).

In general, PSAs are intended for being used at ambient temperature. Therefore, the viscoelastic properties of the PUs synthetized with PPG + PTHF were also determined by frequency sweep experiments at $25^{\circ} \mathrm{C}$ (Figure $7(\mathrm{a})$ ). Similar trends of the values of 
496

497

498

499

500

501

502

503

504

505

506

507

508

509

510

511

512

513

514

515

516

517

518

519

520

521

522

523

524

525

526

527

528

529

530

531

532

533

534

535

536

537

538

539

540
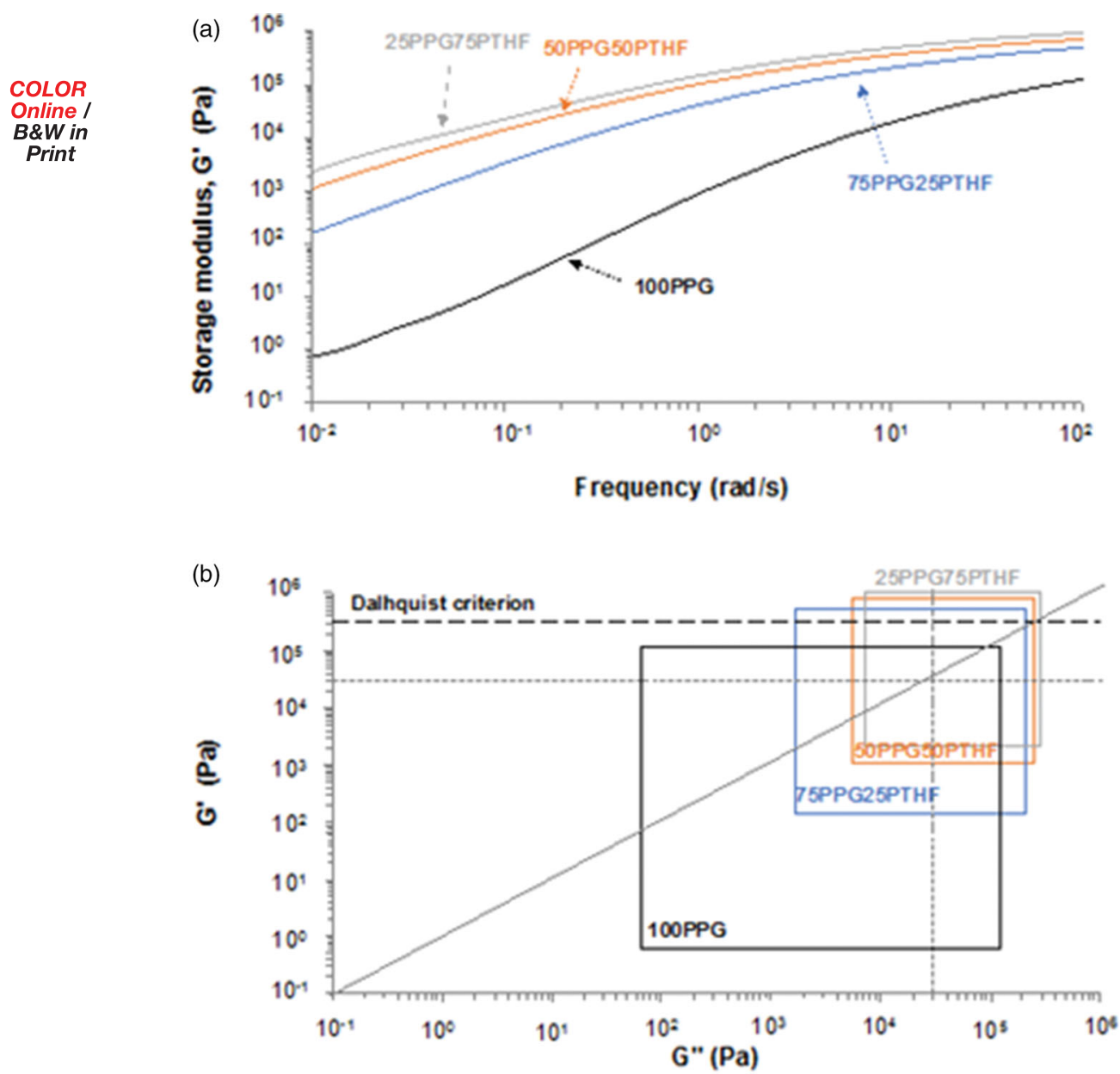

Figure 7. (a) Variation of the storage modulus $\left(G^{\prime}\right)$ as a function of the frequency at $25^{\circ} \mathrm{C}$. (b) Viscoelastic windows of the PUs synthetized with PPG + PTHF mixtures. Solid line corresponds to $\tan$ delta $=1\left(G^{\prime}=G^{\prime \prime}\right)$ and the dashed line defines the four quadrant regions of the viscoelastic window.

$\mathrm{G}^{\prime}$ are obtained in Figures 6(a) and 7(a). According to Chu [31], an adequate combination of adhesion (tack, peel) and cohesion (shear) properties in PSAs can be expected when the $\mathrm{G}^{\prime}$ value measured at $0.1 \mathrm{rad} / \mathrm{s}$ is $(2-4) \times 10^{4} \mathrm{~Pa}$ and the $\left(\mathrm{G}^{\prime}\right.$ at $\left.100 \mathrm{rad} / \mathrm{s}\right) /\left(\mathrm{G}^{\prime}\right.$ at $0.1 \mathrm{rad} / \mathrm{s}$ ) ratio is $5-300$. In general, the PUs synthetized with PPG + PTHF show values of $\mathrm{G}^{\prime}$ at $0.1 \mathrm{rad} / \mathrm{s}$ lower than the ones established by Chu indicating that good tack can be expected (Table 3). The values of $\mathrm{G}^{\prime}$ at $100 \mathrm{rad} / \mathrm{s}$ of the PUs increase by increasing their HS content, this is an indication of higher cohesion by increasing their PTHF content. Furthermore, the $\left(\mathrm{G}^{\prime}\right.$ at $\left.100 \mathrm{rad} / \mathrm{s}\right) /\left(\mathrm{G}^{\prime}\right.$ at $\left.0.1 \mathrm{rad} / \mathrm{s}\right)$ ratio varies between 42 and 140 in the PUs synthetized with PPG + PTHF, the values are within the range proposed by Chu.

Chang has proposed the viscoelastic windows for assessing the type of PSA [32]. The viscoelastic windows were obtained by plotting the storage $\left(G^{\prime}\right)$ and loss $\left(G^{\prime \prime}\right)$ moduli at $0.01 \mathrm{rad} / \mathrm{s}$ (low frequency) - related to the bonding process - and at $100 \mathrm{rad} /$ 
Table 4. Probe tack, holding time and $180^{\circ}$ peel strength at $25^{\circ} \mathrm{C}$ of the PUs synthetized with PPG + PTHF mixtures.

\begin{tabular}{lcccc}
\hline PU PSA & Tack $(\mathrm{kPa})$ & Holding time $(\mathrm{min})$ & $180^{\circ}$ peel strength $(\mathrm{N} / \mathrm{cm})$ & Locus of failure $^{\mathrm{a}}$ \\
\hline 100PPG PSA & $436 \pm 21$ & $5 \pm 0.4$ & $0.2 \pm 0.0$ & CA \\
75PPG25PTHF PSA & $634 \pm 16$ & $609 \pm 109$ & $2.6 \pm 0.1$ & CA \\
50PPG50PTHF PSA & $228 \pm 30$ & $>3$ days & $15.5 \pm 1.5$ & $\mathrm{~A}$ \\
25PPG75PTHF PSA & $11 \pm 4$ & $>3$ days & $9.6 \pm 0.8$ & SS
\end{tabular}

${ }^{\mathrm{a}} \mathrm{CA}$ : cohesive failure of the adhesive; A: adhesion; SS: stick-slip.

Table 5. Composition, hard segments (HS) content and relative contributions of the free and hydrogen bonded urethane groups of the PUs synthesized with $50 \mathrm{wt} \%$ PPG $+50 \mathrm{wt} \%$ PTHF and different $\mathrm{NCO} / \mathrm{OH}$ ratios.

\begin{tabular}{|c|c|c|c|c|c|}
\hline \multirow[b]{2}{*}{ PU } & \multirow[b]{2}{*}{ PTHF (wt\%) } & \multirow[b]{2}{*}{$\mathrm{NCO} / \mathrm{OH}$} & \multirow[b]{2}{*}{ HS (\%) } & \multicolumn{2}{|c|}{ Relative contribution of species (\%) } \\
\hline & & & & $\begin{array}{l}\text { Free urethane } \\
\left(1730-1729 \mathrm{~cm}^{-1}\right)\end{array}$ & $\begin{array}{l}\text { H-bonded urethane } \\
\left(1711-1709 \mathrm{~cm}^{-1}\right)\end{array}$ \\
\hline 1.05-PPG + PTHF & 50 & 1.05 & 14.0 & 39 & 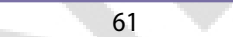 \\
\hline 1.10-PPG + PTHF & 50 & 1.10 & 16.7 & 74 & 26 \\
\hline 1.20-PPG + PTHF & 50 & 1.20 & 19.4 & 38 & 62 \\
\hline 1.35-PPG + PTHF & 50 & 1.35 & 22.0 & 37 & 63 \\
\hline
\end{tabular}

$\mathrm{s}$ (high frequency) - related to the de-bonding process - of the frequency sweep plate -plate rheological curves at $25^{\circ} \mathrm{C}$ of Figure $7(\mathrm{a})$. The viscoelastic windows of the PUs synthetized with PPG + PTHF (Figure 7(b)) show that all PUs satisfied the Dahlquist criterion $\left(\mathrm{G}^{\prime}<3 \times 10^{5} \mathrm{~Pa}\right)$, and they are general purpose PSAs (they are located in the center of the quadrants), except 100PPG polyurethane that is a removable PSA (lower left quadrant).

Table 4 shows the tack, holding time and $180^{\circ}$ peel strength values at $25^{\circ} \mathrm{C}$ of the PU PSAs synthetized with PPG + PTHF blends. 100PPG PSA shows excellent tack, but poor cohesion and low peel strength, likely associated with the dominance of the free urethane groups and low HS content. The addition of $25 \mathrm{wt} \%$ PTHF improves the tack, $180^{\circ}$ peel strength, and cohesion due to the increase of the contribution of the H-bonded urethane groups and the increase of HS content. On the other hand, the PSAs made with $50 \mathrm{wt} \%$ or more PTHF, i.e. 50PPG50PTHF and 25PPG75PTHF PSAs, have higher $180^{\circ}$ peel strength and cohesion, but at the expense of tack. Therefore, a PU PSA with good tack, adequate peel strength and high cohesion cannot be obtained.

\subsection{Variation of the hard segments content of the polyurethanes by changing the $\mathrm{NCO} / \mathrm{OH}$ ratio}

According to Table 4, the PU PSA synthesized with $50 \mathrm{wt} \%$ PPG $+50 \mathrm{wt} \%$ PTHF blend shows an adequate cohesion, high $180^{\circ}$ peel strength and the locus of failure is adhesion to the metal substrate, but the tack is low. Therefore, additional PUs with different hard segments content ( $\mathrm{HS}=14-22 \%$ by weight) were synthesized with $50 \mathrm{wt} \%$ PPG $+50 \mathrm{wt} \%$ PTHF blend by changing the $\mathrm{NCO} / \mathrm{OH}$ ratio (1.05-1.35) (Table 5). The increase of the $\mathrm{NCO} / \mathrm{OH}$ ratio should produce shorter prepolymer units and higher number of BD-prepolymer hard segments (Figure 1), this will cause a different 


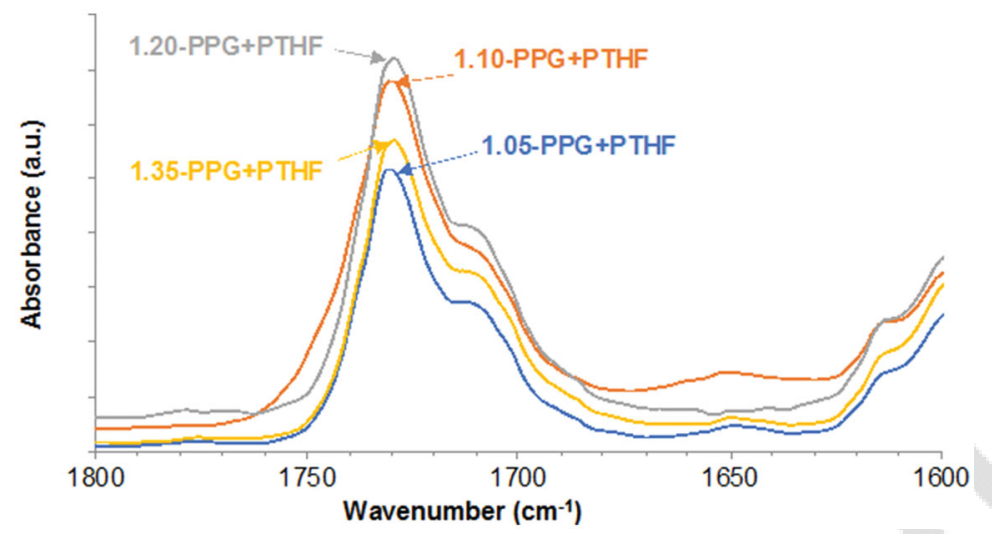

Figure 8. Carbonyl region $\left(1800-1600 \mathrm{~cm}^{-1}\right)$ of the ATR-IR spectra of the PUs synthesized with $50 \mathrm{wt} \%$ PPG $+50 \mathrm{wt} \%$ PTHF and different $\mathrm{NCO} / \mathrm{OH}$ ratios.

distribution of the urethane groups in the polymeric chains which will change the interactions between them.

The chemical structure of the PUs synthesized with $50 \mathrm{wt} \%$ PPG $+50 \mathrm{wt} \%$ PTHF and different $\mathrm{NCO} / \mathrm{OH}$ ratios was analyzed by ATR-IR spectroscopy. Figure 8 shows the carbonyl region of the ATR-IR spectra in which the contributions of the free $\left(1730-1729 \mathrm{~cm}^{-1}\right)$ and H-bonded $\left(1711-1709 \mathrm{~cm}^{-1}\right)$ urethane groups can be distinguished.

The curve fitting of the carbonyl region shows that the H-bonded urethane groups are dominant in all PUs except in 1.10-PPG + PTHF in which, unexpectedly, more important contribution of the free urethane groups (i.e. not in hard domains) is obtained (Table 5). It can be expected that the increase of the HS content in the PU by increasing the $\mathrm{NCO} / \mathrm{OH}$ ratio should increase the percentage of the $\mathrm{H}$-bonded urethane groups, but all PUs synthesized with $50 \mathrm{wt} \%$ PPG + $50 \mathrm{wt} \%$ PTHF show similar percentages and the one made with $\mathrm{NCO} / \mathrm{OH}=1.10$ does not follow the expected trend. TGA traces also show a similar trend (see below), this indicates an unexpected particular structure in the PUs synthesized with $50 \mathrm{wt} \%$ PPG $+50 \mathrm{wt} \%$ PTHF and different $\mathrm{NCO} / \mathrm{OH}$ ratios. Considering that the molecular weight of PTHF is $1000 \mathrm{Da}$ and all PUs have the same PTHF content, the percentages of $\mathrm{H}$-bonded urethanes in the vicinity of the PTHF soft segments should be similar, the influence of the $\mathrm{NCO} / \mathrm{OH}$ ratio will be minor (Figure 9). On the other hand, when the $\mathrm{NCO} / \mathrm{OH}$ ratio is 1.10 , the number of the urethane hard segments obtained by reacting the prepolymer and 1,4butanediol is not very different than the one obtained with $\mathrm{NCO} / \mathrm{OH}$ ratio of 1.05 , but the length of the prepolymer units in the polymeric chain is somewhat longer, this may disrupt the interactions between the urethane groups. According to Figure 9, the interactions between the urethane groups are less in 1.10-PPG + PTHF than in 1.05PPG + PTHF which lead to higher degree of micro-phase separation and higher mobility of the soft segments.

Only one glass transition of the soft segments is observed in the DSC thermograms of the PUs synthesized with $50 \mathrm{wt} \%$ PPG $+50 \mathrm{wt} \%$ PTHF and different $\mathrm{NCO} / \mathrm{OH}$ ratios (Table 6) and the value of $T_{\mathrm{g}}$ increases from -54 to $-46^{\circ} \mathrm{C}$ by increasing the 
631 632

633

634

635

636

637

638

639

640

641

642

643

644

645

646

647

648

649

650

651

652

653

654

655

656

657

658

659

660

661

662

663

664

665

666

667

668

669

670

671

672

673

674

675
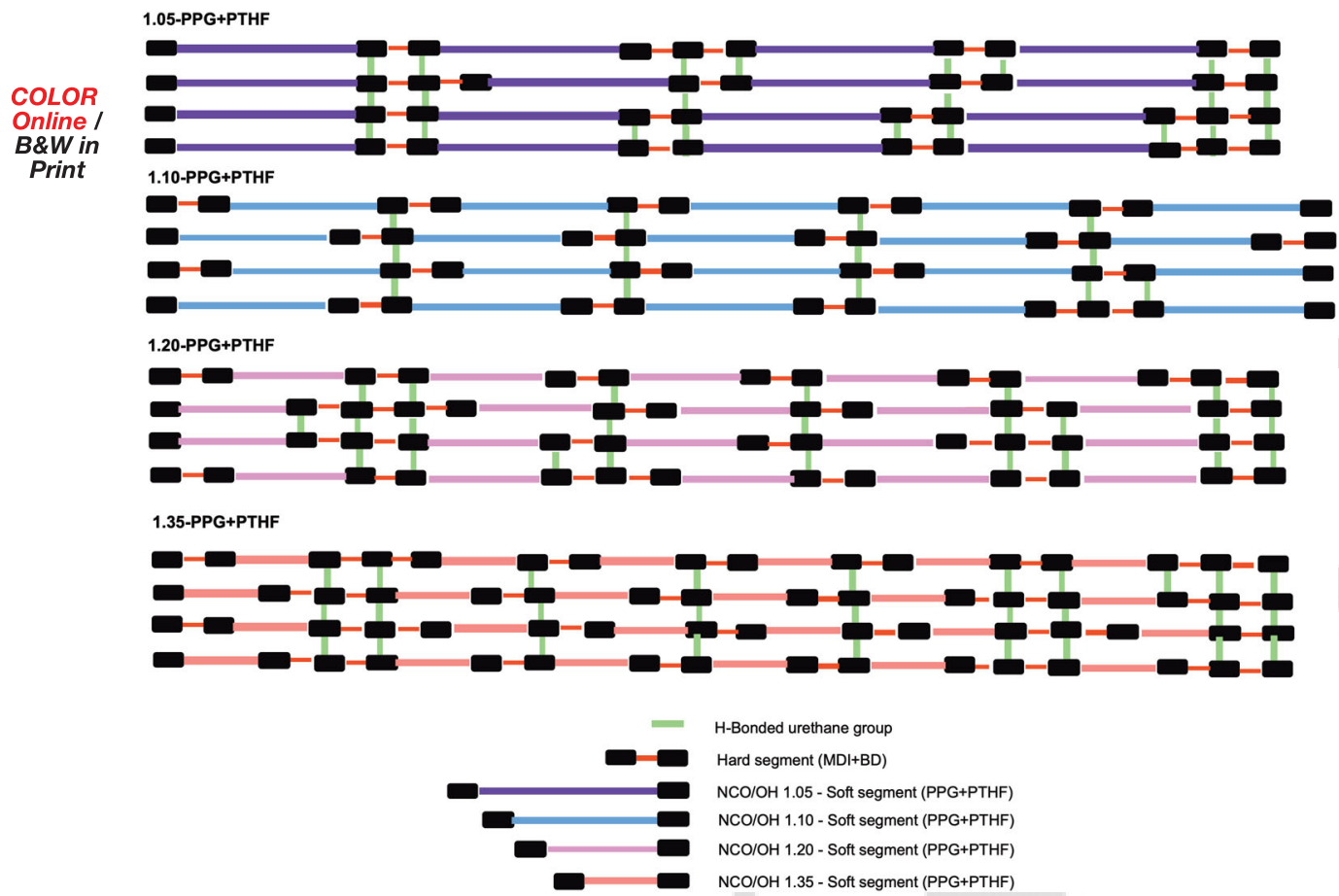

Figure 9. Scheme of the interactions between the hard segments in the PUs synthesized with $50 \mathrm{wt} \%$ PPG $+50 \mathrm{wt} \%$ PTHF and different NCO/OH ratios.

Table 6. Glass transition temperature $\left(T_{\mathrm{g}}\right)$ obtained from DSC experiments, and the temperatures and weight losses of the thermal decompositions obtained from DTGA experiments in the PUs synthesized with $50 \mathrm{wt} \% \mathrm{PPG}+50 \mathrm{wt} \%$ PTHF and different $\mathrm{NCO} / \mathrm{OH}$ ratios.

\begin{tabular}{lcccccc}
\hline & & \multicolumn{2}{c}{ 1st degradation } & & \multicolumn{2}{c}{ 2nd degradation } \\
\cline { 2 - 4 } PU & $T_{\mathrm{g}}\left({ }^{\circ} \mathrm{C}\right)$ & $T_{1}\left({ }^{\circ} \mathrm{C}\right)$ & Weight loss $1 \%)$ & & $T_{2}\left({ }^{\circ} \mathrm{C}\right)$ & Weight loss $(\%)$ \\
\hline 1.05-PPG + PTHF & -54 & 332 & 24 & & 397 & 74 \\
1.10-PPG + PTHF & -50 & 339 & 26 & & 386 & 72 \\
1.20-PPG + PTHF & -47 & 326 & 27 & & 385 & 71 \\
1.35-PPG + PTHF & -46 & 340 & 25 & & 399 & 73 \\
\hline
\end{tabular}

hard segments content (or the $\mathrm{NCO} / \mathrm{OH}$ ratio). On the other hand, the DTGA plots show two thermal degradations at $326-340^{\circ} \mathrm{C}$ (urethane hard domains) and $385-399^{\circ} \mathrm{C}$ (soft domains) in the PUs synthesized with $50 \mathrm{wt} \% \mathrm{PPG}+50 \mathrm{wt} \%$ PTHF and different $\mathrm{NCO} / \mathrm{OH}$ ratios (Figure 10). The weight losses of the soft domains (71-74wt\%) are higher than the ones of the hard domains (24-27wt\%), but they do not vary significantly with the $\mathrm{NCO} / \mathrm{OH}$ ratio (Table 6); the similarity in weight losses of the hard domains in PUs made with different $\mathrm{NCO} / \mathrm{OH}$ ratio agrees with the similarity in the percentages of $\mathrm{H}$-bonded urethanes (Table 5). On the other hand, the temperature of the thermal decomposition of the soft domains is lower and the one of the hard domains in 1.10-PPG + PTHF polyurethane is higher than for the rest of the PUs, this is an indication of lower interactions between the soft domains, in agreement with the ATR-IR spectra. 




Figure 10. Variation of the derivative of the weight as a function of the temperature for PUs synthesized with $50 \mathrm{wt} \%$ PPG $+50 \mathrm{wt} \%$ PTHF and different $\mathrm{NCO} / \mathrm{OH}$ ratios.

The different structure of the 1.10-PPG + PTHF polyurethane is also evidenced in the plots of $G^{\prime}$ versus temperature in which the highest $G^{\prime}$ values correspond to 1.10PPG + PTHF (Figure 11(a)). The increase of the HS content should increase the storage modulus of the PU, and this trend is shown in Figure 11(a), i.e. the lowest value corresponds to 1.05-PPG + PTHF, the $\mathrm{G}^{\prime}$ value is exceptionally high in 1.10PPG + PTHF (Table 7). Similarly, the temperature at the cross-over of $\mathrm{G}^{\prime}$ and $\mathrm{G}^{\prime \prime}$ in the rheological plots increases by increasing the $\mathrm{NCO} / \mathrm{OH}$ ratio but the value of 1.10-PPG + PTHF polyurethane is much higher than expected (Table 7) due to the dominant contribution of the free urethane groups and higher degree of micro-phase separation with respect to the other PUs (Table 5).

According to Table 7, the increase of the HS content increases the storage moduli at 0.1 and $100 \mathrm{rad} / \mathrm{s}$ of the PUs, the values of the 1.10-PPG + PTHF polyurethane are higher than expected, i.e. all PUs should have a good balance between adhesion and cohesion properties, particularly 1.10-PPG + PTHF. Additionally, the ( $\mathrm{G}^{\prime}$ at $\left.100 \mathrm{rad} / \mathrm{s}\right) /$ $\left(\mathrm{G}^{\prime}\right.$ at $\left.0.1 \mathrm{rad} / \mathrm{s}\right)$ ratio satisfied Chús prediction anticipating good cohesion of the PUs. On the other hand, the viscoelastic windows show that the PUs synthetized with NCO/ $\mathrm{OH}$ ratios from 1.05 to 1.20 are typical general purpose PSAs, whereas the 1.35PPG + PTHF polyurethane is a high shear PSA (Figure 11(b)).

The adhesion properties of the PU PSAs synthesized with $50 \mathrm{wt} \%$ PPG $+50 \mathrm{wt} \%$ $\mathrm{PTHF}$ and different $\mathrm{NCO} / \mathrm{OH}$ ratios are given in Table 8. The increase of the HS content (or the increase of the $\mathrm{NCO} / \mathrm{OH}$ ratio) decreases the tack of the PU PSA, except in 1.10-PPG + PTHF polyurethane which has higher mobility of the soft segments due to higher contribution of the free urethane groups. The $\mathrm{PUs}$ with $\mathrm{NCO} / \mathrm{OH}$ ratio of 1.10-1.35 have excellent cohesion (holding time $>3$ days) and the loci of failure observed in the joints tested by $180^{\circ}$ peel strength correspond to adhesion to the metallic substrate. The highest values of $180^{\circ}$ peel strength are found in the joints made with 1.10-PPG + PTHF and 1.20-PPG + PTHF PSAs and both PSAs show a good balance between the adhesion and cohesion properties, but 1.10-PPG + PTHF also has an excellent tack. 

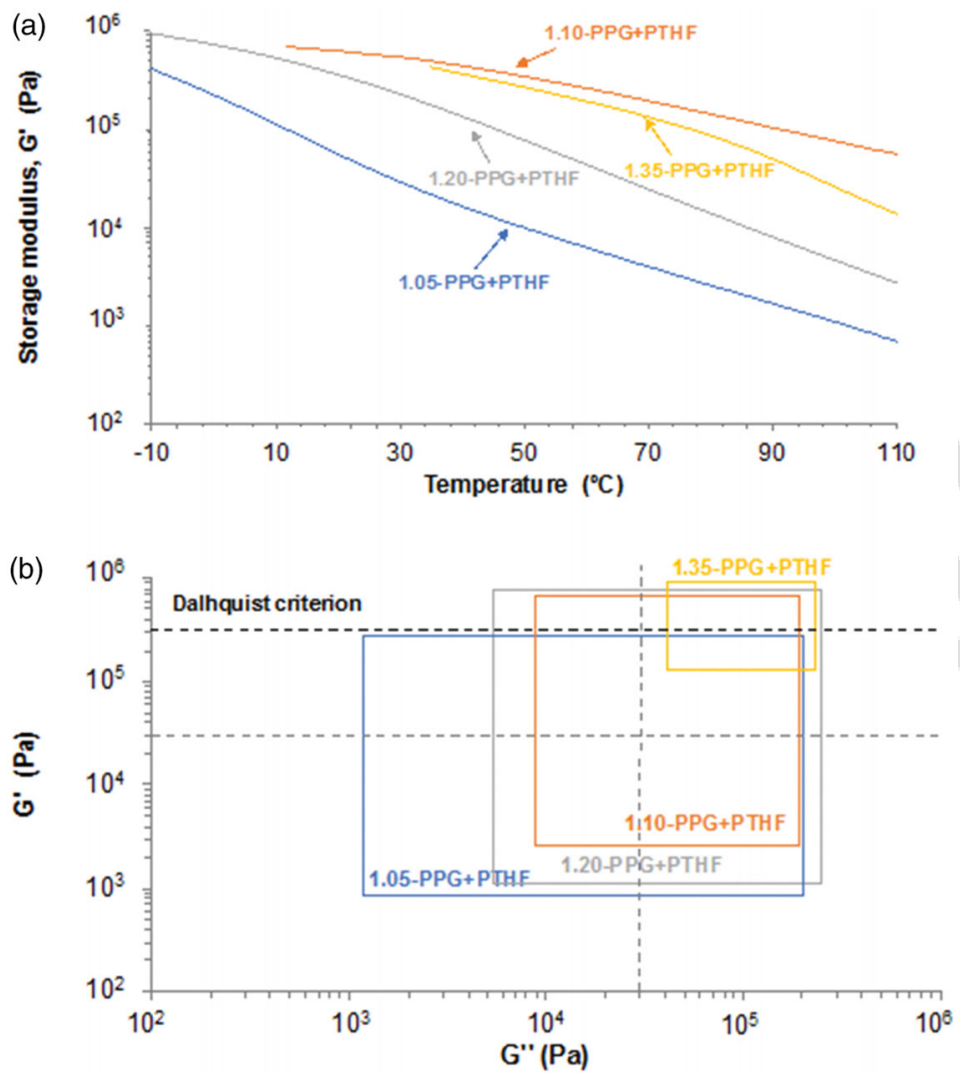

Figure 11. (a) Variation of the storage modulus $\left(\mathrm{G}^{\prime}\right)$ at $25^{\circ} \mathrm{C}$ as a function of the temperature and (b) viscoelastic windows of the PUs synthesized with $50 \mathrm{wt} \%$ PPG $+50 \mathrm{wt} \%$ PTHF and different $\mathrm{NCO} / \mathrm{OH}$ ratios. Solid line corresponds to $\tan$ delta $=1\left(\mathrm{G}^{\prime}=\mathrm{G}^{\prime \prime}\right)$ and the dashed line corresponds to the four quadrant regions of the viscoelastic window.

Table 7. Values of the temperature $\left(T_{\text {cross-over }}\right)$ and modulus $\left(\mathrm{G}_{\text {cross-over }}\right)$ at the crossing of the storage and loss moduli, storage modulus at $25^{\circ} \mathrm{C}\left(\mathrm{G}^{\prime}{ }_{1 \mathrm{~Hz}}\right)$, and storage moduli at $0.01 \mathrm{rad} / \mathrm{s}$ and $100 \mathrm{rad} / \mathrm{s}$ of the PUs synthesized with $50 \mathrm{wt} \%$ PPG $+50 \mathrm{wt} \%$ PTHF and different NCO/OH ratios.

\begin{tabular}{|c|c|c|c|c|c|c|}
\hline \multirow[b]{2}{*}{ PU } & \multicolumn{3}{|c|}{ Temperature sweep } & \multicolumn{3}{|c|}{ Frequency sweep at $25^{\circ} \mathrm{C}$} \\
\hline & $T_{\text {cross-over }}\left({ }^{\circ} \mathrm{C}\right)$ & $G_{\text {cross-over }}(\mathrm{Pa})$ & $\mathrm{G}^{\prime}{ }_{1 \mathrm{~Hz}}$ at $25^{\circ} \mathrm{C}(\mathrm{Pa})$ & $\mathrm{G}_{0.1 \mathrm{rad} / \mathrm{s}}^{\prime}(\mathrm{kPa})$ & $\mathrm{G}_{100 \mathrm{rad} / \mathrm{s}}^{\prime}(\mathrm{kPa})$ & $\begin{array}{c}\mathrm{G}_{100 \mathrm{rad} / \mathrm{s}} / \\
\mathrm{G}_{0.1 \mathrm{rad} / \mathrm{s}}^{\prime}\end{array}$ \\
\hline 1.05-PPG + PTHF & 7 & $1.4 \cdot 10^{5}$ & $4.0 \cdot 10^{6}$ & 4.0 & 283.6 & 71 \\
\hline 1.10-PPG + PTHF & 84 & $1.3 \cdot 10^{5}$ & $5.7 \cdot 10^{5}$ & 27.4 & 731.8 & 27 \\
\hline 1.20-PPG + PTHF & 38 & $1.4 \cdot 10^{5}$ & $2.8 \cdot 10^{5}$ & 14.8 & 730.5 & 49 \\
\hline 1.35-PPG + PTHF & 96 & $3.4 \cdot 10^{4}$ & - & 216 & 985.1 & 5 \\
\hline
\end{tabular}

Table 8. Probe tack, holding time and $180^{\circ}$ peel strength at $25^{\circ} \mathrm{C}$ of the PUs synthetized with $50 \mathrm{wt} \%$ PPG $+50 \mathrm{wt} \%$ PTHF and different $\mathrm{NCO} / \mathrm{OH}$ ratios.

\begin{tabular}{|c|c|c|c|c|}
\hline PU PSA & Tack (kPa) & Holding time (min) & $180^{\circ}$ peel strength $(\mathrm{N} / \mathrm{cm})$ & Locus of failure $^{a}$ \\
\hline 1.05-PPG + PTHF PSA & $278 \pm 17$ & $218 \pm 16$ & $1.0 \pm 0.1$ & CA \\
\hline 1.10-PPG + PTHF PSA & $572 \pm 87$ & $>3$ days & $53.3 \pm 7.7$ & A \\
\hline 1.20-PPG + PTHF PSA & $228 \pm 30$ & $>3$ days & $15.5 \pm 1.5$ & A \\
\hline 1.35-PPG + PTHF PSA & $33 \pm 5$ & $>3$ days & $0.5 \pm 0.0$ & A \\
\hline
\end{tabular}

${ }^{\mathrm{a}} \mathrm{CA}$ : cohesive failure of the adhesive; $\mathrm{A}$ : adhesion. 


\section{Conclusions}

Thermoplastic poly(ether-urethane)s with different hard segments contents intended for PSAs have been prepared by using blends of two polyether polyols of different nature and molecular weight. The increase of the hard segments content (by increasing the PTHF content or by increasing the $\mathrm{NCO} / \mathrm{OH}$ ratio) had a great influence on the adhesion and cohesion properties of the PSAs because of the different length and distribution of the hard and soft segments, and the extent of micro-phase separation. The increase of the PTHF content decreased the degree of micro-phase separation between the hard and soft segments due to the increase of the HS content; furthermore, the less contribution of the pendant methyl group in the soft segments by increasing the PTHF content enhanced the interactions between the hard segments leading to improved cohesion of the PSAs. On the other hand, a balanced and particular structure was obtained in the PU made $50 \mathrm{wt} \% \mathrm{PPG}+50 \mathrm{wt} \% \mathrm{PTHF}$ blend and $\mathrm{NCO} / \mathrm{OH}$ ratio of 1.10 in which the percentage of the free urethane groups, the storage modulus and the temperature at the cross-over between the storage and loss moduli are higher, and the temperature of decomposition of the soft segments was lower than in the rest of the PUs synthesized with different $\mathrm{NCO} / \mathrm{OH}$ ratios. Furthermore, the most PUs synthesized with different HS content are general purpose PSAs. 1.10-PPG + PTHF and 1.20-PPG + PTHF PSAs showed the best balance between adhesion and cohesion properties, but 1.10-PPG + PTHF PSA provided an excellent tack too.

\section{Acknowledgments}

Authors thank Repsol for supplying the PPG polyol.

\section{Disclosure statement}

Q2 No potential conflict of interest was reported by the author(s).

\section{ORCID}

José Miguel Martín-Martínez (D) http://orcid.org/0000-0002-7230-6581

\section{References}

[1] Satas D, Satas AM. Hospital and first aid products. In: Satas D, editor. Handbook of pressure sensitive adhesive technology. New York: Van Nostrand Reinhold; 1989. p. 627-642.

[2] Feldstein MM, Siegel RA. Molecular and nanoscale factors governing pressure-sensitive adhesion strength of viscoelastic polymers. J Polym Sci B Polym Phys. 2012;50(11): 739-772.

[3] Yilgör I, Yilgör E, Wilkes GL. Critical parameters in designing segmented polyurethanes and their effect on morphology and properties: a comprehensive review. Polymer. 2015; 58:A1-A36.

[4] Datta J, Kasprzyk P. Thermoplastic polyurethanes derived from petrochemical or renewable resources: a comprehensive review. Polym Eng Sci. 2018;58(S1):E14-E35. 
[5] He Y, Xie D, Zhang X. The structure, microphase-separated morphology, and property of polyurethanes and polyureas. J Mater Sci. 2014;49(21):7339-7352.

[6] Martin DJ, Meijs GF, Renwick G, et al. The effect of average soft segment length on morphology and properties of a series of polyurethane elastomers. I. Characterization of the series. J Appl Polym Sci. 1996;62(9):1377-1386.

[7] Klinedinst DB, Yilgör I, Yilgör E, et al. The effect of varying soft and hard segment length on the structure-property relationships of segmented polyurethanes based on a linear symmetric diisocyanate, 1,4-butanediol and PTMO soft segments. Polymer. 2012; 53(23):5358-5366.

[8] Rogulska M, Kultys A, Lubczak J. New thermoplastic polyurethane elastomers based on aliphatic-aromatic chain extenders with different content of sulfur atoms. J Therm Anal Calorim. 2015;121(1):397-340.

[9] Sánchez-Adsuar MS, Pastor-Blas MM, Martín-Martínez JM. Properties of polyurethane elastomers with different hard/soft segment ratio. J Adhes. 1998;67(1-4):327-345.

[10] Dreyfuss P, Larive DE. Effect of chemical Mc of polyurethanes on adhesion to glass. J Adhes. 1989;27(2):105-121.

[11] Agrawal RK, Drzal LT. Adhesion mechanisms of polyurethanes to glass surfaces. Part II. Phase separation in polyurethanes and its effects on adhesion to glass. J Adhes Sci Technol. 1995;9:381-1400.

[12] Mirhosseini MM, Haddadi-Asl V, Jouibari IS. A simple and versatile method to tailor physicochemical properties of thermoplastic polyurethane elastomers by using novel mixed soft segments. Mater Res Express. 2019;6(6):065314.

[13] Czech Z, Hinterwaldner R. Pressure sensitive adhesives based on polyurethanes. In: Benedek I, Feldstein MM, editors. Handbook of pressure sensitive adhesive and products. Technology of pressure-sensitive adhesives and products. Boca Raton: CRC Press; 2009. Chapter 11. p. 1-21.

[14] Czech Z, Milker R, Malec A. Crosslinking of PUR-PSA water-borne systems. Rev Adv Mater Sci. 2006;12:189-199.

[15] Singh AK, Mehr DS, Niyogi UK, et al. Effect of tackifier and crosslinkers on electron beam curable polyurethane pressure sensitive adhesive. Radiat Phys Chem. 2012;81(5): $547-552$.

[16] Nakamura Y, Nakano S, Ito K, et al. Adhesion properties of polyurethane pressure-sensitive adhesive. J Adhes Sci Tech. 2013;27(3):263-277.

[17] Yuan Y, Zhang Y, Fu X, et al. Silane-terminated polyurethane applied to a moisturecurable pressure-sensitive adhesive using triethoxysilane. RSC Adv. 2016;6(87): 83688-83696.

[18] Yuan Y, Zhang Y, Fu X, et al. Molecular design for silane-terminated polyurethane applied to moisture-curable pressure-sensitive adhesive. J Appl Polym Sci. 2017;134(37): 45292-45300.

[19] Akram N, Gurney RS, Zuber M, et al. Influence of polyol molecular weight and type on the tack and peel properties of waterborne polyurethane pressure-sensitive adhesives. Macromol React Eng. 2013;7(10):493-503.

[20] Akram N, Zia KM, Saeed M, et al. Impact of macrodiols on the adhesion strength of polyurethane pressure-sensitive adhesives. J Appl Polym Sci. 2018;135(45):46635.

[21] Akram N, Zia KM, Saeed M, et al. Role of isophorone diisocyanate in the optimization of adhesion tendency of polyurethane pressure sensitive adhesives. J Appl Polym Sci. 2018;135(45):46635.

[22] Akram N, Zia KM, Saeed M, et al. Morphological studies of polyurethane based pressure sensitive adhesives by tapping mode atomic force microscopy. J Polym Res. 2018; 25:194.

[23] Akram N, Zia KM, Saeed M, et al. Compositional effect on the deformation behavior of polyurethane pressure-sensitive adhesive thin films. J Appl Polym Sci. 2020;137(8): 48395. 
[24] Fuensanta M, Martín-Martínez JM. Thermoplastic polyurethane coatings made with mixtures of polyethers of different molecular weights with pressure sensitive adhesion property. Prog Org Coat. 2018;118:148-156.

[25] Fuensanta M, Martín-Martínez JM. Thermoplastic polyurethane pressure sensitive adhesives made with mixtures of polypropylene glycols of different molecular weights. Int J Adhes Adhes. 2019;88:81-90.

[26] Ahn TO, Choi IS, Jeong HM, et al. Thermal and mechanical-properties of thermoplastic polyurethane elastomers from different polymerization methods. Polym Int. 1993; 31(4):329-333.

[27] Paik Sung CS, Hu CB, Wu CS. Properties of segmented poly(urethaneureas) based on 2,4-toluene diisocyanate. 1. Thermal transitions, X-ray studies, and comparison with segmented poly(urethanes). Macromolecules. 1980;13(1):111-116.

[28] Mattia J, Painter P. A comparison of hydrogen bonding and order in a polyurethane and poly(urethane-urea) and their blends with poly(ethylene glycol). Macromolecules. 2007;40(5):1546-1554.

[29] Liu L, Wu Y, Zhu Z. Internal structure and crystallinity investigation of segmented thermoplastic polyurethane elastomer degradation in supercritical methanol. Polym Degrad Stab. 2017;140:17-24.

[30] Dahlquist CA. Pressure-sensitive adhesives. In: Patrick RL, editor. Treatise on adhesion and adhesives. New York: Marcel Dekker Inc.; 1969. p. 219-260.

[31] Chu SG. Dynamic mechanical properties of pressure-sensitive adhesives. In: Lee LH, editor. Adhesive bonding. New York: Plenum Press; 1991. p. 97-137.

[32] Chang EP. Viscoelastic properties of pressure-sensitive adhesives. J Adhes. 1997; 60(1-4):233-248. 